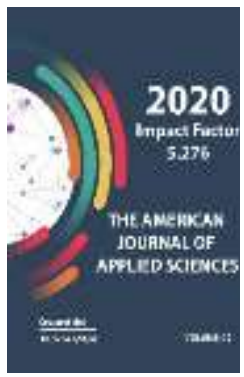

\title{
Landscaph-Land Reclamation Approach In The Study Of Conical Landscape Complexes
}

\author{
O.M.Kuziboeva
}

Associate Professor of Kokand State Pedagogical Institute, Uzbekistan

\begin{abstract}
Journal Website: http://usajournalshub.c om/index,php/tajas

Copyright: Original content from this work may be used under the terms of the creative commons attributes 4.0 licence.
\end{abstract}

\section{ABSTRACT}

This article devoted to changing conic fields to anthropogenic landscapes under anthropogenic effect. Author wrote about principles of meliorative actions and wrong using lands' outcomes.

\section{KEYWORDS}

Melioration, landscape-meliorative marking, cadastre, place type, areal, place (phazy), natural and anthropogenic landscape.

\section{INTRODUCTION}

Landscape complexes of all types and scales present in nature, including landscape complexes of the Sokh conical distribution, are also a single and complex structural natural anthropogenic product. The reclamation status of geocomplexes is also complex and varied depending on the surface structure, slope, lithological composition, depth of groundwater level, salinity and swampiness of soils and other characteristics. For many years, a component or natural geographical approach has been used to address the use of nature, the 
modification of landscape complexes and the implementation of reclamation measures to optimize them. Methods of use in this direction VS Aneshko (1974), DL Armand (1975), LV Dunin-Barkovsky (1976), AA Rafikov (1976), AN Oliferov (1978) , A.M.Shulgin (1980), A.A.Chibilev (1982) and others.

\section{MATERIALS AND METHODS}

The component-specific natural geographical approach to the development of natural complexes does not deny that the geographical components are inextricably linked in the justification of reclamation measures. However, this approach does not make the study and analysis of intercomponent relationships a task in itself. Therefore, the component (natural geographical) approach to this study does not have the ability to fully reveal the relationship between the complexes within the landscape complexes. As a result, regional and local features, local features, diversity of landscape structure, its complex mechanism and paradynamic and paragenetic relationships are neglected in the design of reclamation measures, organization of reclamation works and other complexes. As a result, the reclamation systems that have been built will soon become obsolete.

It should be noted that the component (natural geographical) approach can not serve as a leading criterion in the development of methods such as optimization of the relationship of reclamation systems with landscape complexes, forecasting the gradual development of reclamation landscapes, management of landscape reclamation systems, design of new landscapes. Therefore, in the study of landscape complexes, along with the component (natural geographical) approach, the complex landscape-reclamation approach also has scientific, theoretical and practical significance. Landscape-reclamation approach serves as a scientific basis in the organization of the system of development, analysis, rational use and management of natural complexes, reclamation assessment of landscape complexes, landscape-ameliorative mapping and zoning, creation of landscapeameliorative cadastre. Such an approach defines the main essence, goals and objectives of the landscape-reclamation direction, which is a branch of landscape science. It is known that changing nature, using it for its intended purpose,Develop and propose measures to assess and optimize the reclamation status of landscape complexes will provide close practical assistance to land reclamation, irrigation and farm specialists, determine what types of reclamation and agricultural techniques can be applied to landscape complexes with different local conditions. According to VB Mikhno (1984), reclamation landscape or, in other words, landscapereclamation approach solves complex problems associated with the transformation, qualitative assessment, optimization and creation of landscape-reclamation cadastres of landscape complexes. Such tasks include:

1) Development of principles and methods of reclamation of landscape complexes;

2) Development of landscape reclamation research;

3) Analysis of the interaction of reclamation systems with landscape complexes;

4) Forecasting the functional state of landscape and reclamation systems;

5) Design of neo-landscapes (new landscapes);

6) To study the regional features of land reclamation.

VB Mikhno (1984) admits that the reclamation of landscape complexes of different categories 
and at any taxonomic scale requires substantiation of such principles as taking into account their regional features, typological features, paragenetic and paradynamic relationships. Landscape scientists initially considered it expedient to take into account the natural conditions of each region when changing nature. The importance of regional conditions in solving the problems of nature change is recognized in the works of $\mathrm{VV}$ Dokuchaev (1953), Al Voeykov (1949), VB Mikhno (1984) and others. VV Dokuchaev admits that it is impossible to successfully engage in nature-changing activities without a deep and comprehensive knowledge and study of local zonal factors. Reclamation measures proposed to specialists should be developed taking into account the natural geographical conditions of a particular region, as well as each place. Regional characteristics of landscape complexes have long been taken into account in land reclamation practice.

Regional complexes are characterized by genetic homogeneity, territorial integrity and induvidual structure. Therefore, in addition to the above examples, when substantiating reclamation measures applied in the optimization of landscape complexes, it is necessary to analyze and take into account their origin, signs of territorial integrity and the specificity of individual structures. Disclosure of regional features of landscape complexes is carried out through natural geographical zoning. Therefore, it is an axiom that the importance of natural geographical zoning for land reclamation does not require proof.

Given the complexity of the structure and reclamation status of the Sokh cone distribution and landscape complexes, we found it necessary to solve the problem of natural geographical zoning for reclamation purposes through micro-zoning. Therefore, the need and appropriateness of the application of the regional principle in the reclamation of landscape complexes is based on experience. Adherence to the regional principle serves as a basis for the creation of long-term and effective reclamation systems.

Typological principle of reclamation of landscape complexes. The study of typological landscape complexes is of great importance in finding an objective solution to the problems of land reclamation and the development of measures for it, as well as in the development of model projects. Typological landscape complexes differ from regional landscape complexes in their features and characteristics, such as their area distribution, genetic inequality, morphological similarity. Local separation and delimitation of typological complexes is carried out on the basis of landscape mapping. Typological landscape complexes (landscape type, place type, urochisha type, and facies type) are composed of natural structures of the same type that are morphologically similar to each other. Therefore, it is not advisable to develop separate reclamation projects for each of their individual morphological units. This requires a large amount of money, although a single structured sample project can be legally replicated and applied to multiple facies, urochis, and locations of the same type. Such experiments provide an opportunity to spend less money.

The principles of taking into account the paradynamic and paragenetic relationships in the reclamation of landscape complexes. The creation of optimal conditions for the interaction between landscape complexes and reclamation systems is directly related to the in-depth study and consideration of the 
paradynamic relationship of natural complexes.

Ameliorated landscape complexes are always in dynamic connection with the bordering natural environment. Such connections occur through the flow of matter and energy. It is important to take into account the process of metabolism and energy in the reclamation of natural and anthropogenic landscape complexes. It should be noted that the definition of paradynamic interactions of landscape complexes can be achieved only through a comprehensive analysis of the process of metabolism of matter and energy.

\section{RESULTS AND DISCUSSIONS}

The southern Fergana cone distribution, especially the Sokhdarya cone distribution area, is characterized by swamp and meadow processes, which are constantly moistened by high groundwater levels, occurring in swamps and salinization, strong development of swamp and meadow vegetation and large amounts of organic residues is characterized by an alternation of aerobic and anaerobic conditions in their decomposition. These processes have long been associated with processes occurring under the influence of irrigated agriculture. The expression of the results of the processes is inextricably linked with the lithological-geomorphological and hydrogeological conditions of the region. The peculiarity of the lithology of the cone distribution is reflected in the mechanical stratification of the quotes. The mechanical composition of the soil and subsoil rocks is aggravated in the direction from the top of the spread to the sides of the lower edge, while the radially elongated slopes and hilly soils also have significant differences.

Very low atmospheric precipitation and high temperatures provide a predominance of capillary rise movement of moisture in this area. In this movement, along with moisture, minerals also move from the bottom up. The result is either marginalization or salinization of soils, depending on the chemical composition of the groundwater mineralization. Salinization is accompanied by a grazing process, and salinity increases when the amount of salts is high.

Irrigated agriculture has made great changes in the natural pasture process in the cone distribution and has formed a separate group of soils with a specific direction of development and stable morphological and physicochemical properties.

The main changes that irrigation has brought to grassland soils are:

First, large amounts of irrigation water disrupted soil water and air regimes. The soil is now periodically moistened not only by capillary flows, but also by the large amount of water supplied. Irrigation water periodically over-moistens the top layers, infiltrating the soil and contacting it with groundwater, which raises the level and causes the soils to become swampy. Anaerobic processes increase in the subsoil and the layer thickness in which these processes predominate increases. The upper layers of the soil develop under conditions of alternating aerobic and anaerobic processes as a result of tillage and small ditches, which have been used since ancient times. They eventually impoverish the soil to humus.

The results of these processes are clearly expressed in soil morphology. They have a light blue-gray color, formed by a relatively large amount of humus and semi-oxide compounds of iron. The subsoil is gleyed. Irrigation water drastically changes the order of groundwater, redistributes salts across the soil section, which are washed away during 
irrigation and carried upwards during irrigation intervals.

Water-soluble salts are washed away by irrigation water to groundwater and increase their mineralization. However, during perennial irrigation, the upper layers of groundwater become fresh, and salts move to the edges of the oasis and from the highlands to the lowlands.

Instead of natural genetic layers, processed layers with favorable water and air properties, good structure are formed. A decrease in the amount of humus occurs.

\section{CONCLUSION}

In the territory of the Sokdarya cone distribution, the specific lithological and geomorphological structure and the associated hydrogeological conditions change in the direction of its periphery from the upper parts, and the nature of the soils changes accordingly. Calmotic soils formed in the upper gravel part of the cone distribution are replaced by unsalted or weakly saline marginalized meadows, meadow-swamps and marshy soils in the middle part of the distribution. They give their place in the peripheral part of the spread, first to weak and medium, then to strongly saline hungry-grass soils. In the middle and lower parts of the cone distribution there are significant changes in the mechanical composition of soils and soil rocks, the level of humus, salinization and swamping of soils in accordance with the mesorelief. Radial elongated elevations are composed of lighter sediments than lowlands, have deeper and less mineralized groundwater, low humus content in soils, and low salinity.

\section{REFERENCES}

1. Abduganiev I. Landscape indicators of oil and gas bearing structures in the southern part of the Fergana Valley // Author. diss. Cand. geogr. sciences.-M .: -1976. -21 s.

2. Abdulkasimov A.A. Physical and geographical regions of the Fergana Basin. Scientific zap. Voronezh. dep. total USSRVoronezh, 1963.

3. Abolin R.I. Fundamentals of naturalhistorical zoning of Soviet Central Asia. // Tr.SAGU, ser XII, Geography, issue 2. -1929.P.12-145.

4. Abdulkasimov A., ибziboeva O. Sokh oyilmasi landscapelarini microzonalashtirish va melioration baxolash. -Samargand, 2009 .- $134 \mathrm{p}$.

5. Babushkin L.N. Physical and geographical areas. // In the book. Fergana Valley. Tashkent: Publishing house of the Academy of Sciences of the Uzbek SSR, 1954. -S. 280304.

6. Boimirzaev K.M. Agro-irrigation nanoscale of oasis landscapes of the Fergana Valley and their rational use (on the example of the Sokh and Chartaksay fan cones). // Autoref.kand.dis. - Tashkent, 1995 --- 21 p.

7. Isakov V.Yu. Gypsum-bearing, arzyk and shokhovy soils of the Fergana Valley, conditions of their formation and ways of rational use: Author's abstract. diss. d. b. D. - Tashkent: NIIPA, 1993. -38 p.

8. Isakov V.Yu., Kuziboeva O. To the characteristics of the soil cover of the fan of the Sokh river. Kyrgyz statehood and problems of intercultural dialogue. Kyrg. Uzb. University. Sat. scientific tr. - Osh, 2003. - ... p.

9. Masudov A. Changes in soil and ecological conditions of the Fergana Valley under anthropogenic impact: Author's abstract. diss. d. b. n. -Tashkent: 
10. Sultanov Yu. Natural conditions and physical-geographical zoning of the southern mountain frame of Fergana // Author. Diss. Cand. geogr. sciences. Kiev, 1965.-21 p. 